\title{
Lifting and exertion injuries decrease after implementation of an integrated hospital-wide safe patient handling and mobilisation programme
}

\author{
Jack T Dennerlein, ${ }^{1,2}$ Elizabeth (Tucker) O'Day, ${ }^{3}$ Deborah F Mulloy, ${ }_{1}^{4}$ \\ Jackie Somerville, ${ }^{5}$ Anne M Stoddard, ${ }^{6}$ Christopher Kenwood, ${ }^{7}$ Erin Teeple, ${ }^{2,8}$ \\ Leslie I Boden, ${ }^{9}$ Glorian Sorensen, ${ }^{6,10}$ Dean Hashimoto ${ }^{3,11,12}$
}

For numbered affiliations see end of article.

\section{Correspondence to} Dr Jack T Dennerlein, Department of Physical Therapy, Movement, and Rehabilitation Sciences, Bouvé College of Health Sciences, Northeastern University, Robinson Hall 301, 360 Huntington Avenue, Boston MA 02215, USA; j.dennerlein@ neu.edu

Received 23 December 2015 Revised 15 September 2016 Accepted 3 October 2016 Published Online First 25 October 2016
CrossMark

\section{To cite: Dennerlein JT,} O’Day E (T), Mulloy DF, et al. Occup Environ Med 2017;74:336-343.

\section{ABSTRACT}

Objective With increasing emphasis on early and frequent mobilisation of patients in acute care, safe patient handling and mobilisation practices need to be integrated into these quality initiatives. We completed a programme evaluation of a safe patient handling and mobilisation programme within the context of a hospitalwide patient care improvement initiative that utilised a systems approach and integrated safe patient equipment and practices into patient care plans.

Methods Baseline and 12-month follow-up surveys of 1832 direct patient care workers assessed work practices and self-reported pain while an integrated employee payroll and injury database provided recordable injury rates collected concurrently at 2 hospitals: the study hospital with the programme and a comparison hospital.

Results Safe and unsafe patient handling practice scales at the study hospital improved significantly $(p<0.0001$ and $p=0.0031$, respectively), with no differences observed at the comparison hospital. We observed significant decreases in recordable neck and shoulder (Relative Risk (RR) $=0.68,95 \% \mathrm{Cl} 0.46$ to 1.00), lifting and exertion $(R R=0.73,95 \% \mathrm{Cl} 0.60$ to 0.89 ) and pain and inflammation ( $R R=0.78,95 \% \mathrm{Cl}$ 0.62 to 1.00 ) injury rates at the study hospital. Changes in rates at the comparison hospital were not statistically significant.

Conclusions Within the context of a patient mobilisation initiative, a safe patient handling and mobilisation programme was associated with improved work practices and a reduction in recordable worker injuries. This study demonstrates the potential impact of utilising a systems approach based on recommended best practices, including integration of these practices into the patient's plan for care.

\section{INTRODUCTION}

Patient handling and mobilisation activities in acute care hospitals are a fundamental aspect of patient care. As of late, there is a strong emphasis on early and frequent patient mobilisation to improve rehabilitation during and after hospitalisation. ${ }^{1}$ Early and frequent patient mobilisation maintains patient hygiene, prevent physical deconditioning and reduce serious complications of immobility. ${ }^{23}$

This increase in patient mobilisation to improve patient care increases the physical demands of

\section{What this paper adds}

- Recent trends in patient care improvement in acute care settings include early and frequent mobilisation of patients; however, this can add to the physical demands on patient care workers increasing their risk of injury.

- This programme evaluation of a hospital-wide safe patient handling and mobilisation programme occurred within the context of integrating worker safety practices associated with patient handling into a larger initiative to improve patient outcomes through early and frequent mobilisation of patients and where safe patient handling and mobilisation equipment and practices were integrated into patients' plan of care.

- Through an extensive worker survey and employee health and safety database implemented as part of another worker safety and health study, the evaluation documents changes in work practices and reduced worker injury rates associated with lifting.

- This research suggest that hospitals should include safe patient handling and mobilisation programmes as part of early patient mobilisation programmes and prescribe safe patient equipment and practices into the specific and individualised care plan for each patient.

hospital workers, hence the risk of injury. Hospital workers have high rates of musculoskeletal disorders $^{4-7}$ most likely in part due to the physical demands associated with patient handling. ${ }^{8}$ Therefore, to prevent worker injuries associated with the expected increase in demands, these quality initiatives need to be implemented with an embedded safe patient handling and mobilisation programme to improve care of the patient and the safety and health of the caregiver. ${ }^{9} 10$

The purpose of this study was to evaluate the impact of a hospital-wide, safe patient handling and mobilisation programme within the context of a healthcare quality improvement initiative that included emphasising early and frequent patient 
mobilisation. Based on their experience, hospital leadership determined that the quality improvement initiative needed to include a comprehensive hospital-wide programme for safe patient handling and mobilisation. The programme design consisted of effective systems approaches described throughout the literature ${ }^{11-14}$ and that of our own experiences. ${ }^{15}{ }^{16} \mathrm{~A}$ unique element of the programme was embedding and integrating the use of safe patient handling and mobilisation equipment and practices into the patient care plan aimed at increasing the patient mobility and aligning the goals of the worker safety programme with the priority of workers to providing care to their patients. ${ }^{17}$

The programme evaluations utilised data generated in the context of a two-hospital study of the health and safety of direct patient care workers that surveyed workers before and after the programme initiation ${ }^{18}$ and developed and maintained an integrated worker health and safety database. ${ }^{5}{ }^{19}$ Through these worker surveys and the administrative database, the programme evaluation measured the impact on patient handling work practices, workers' self-reported musculoskeletal pain symptoms and recordable worker injury rates. Our hypotheses were that (1) patient mobilisation and ergonomic practices; (2) self-reported musculoskeletal pain prevalence and severity and (3) recordable musculoskeletal injuries among patient care staff would all improve between preimplementation and postimplementation of the programme.

\section{METHODS}

This programme evaluation was completed in collaboration between Partners HealthCare and the Harvard T.H. Chan School of Public Health Center for Work, Health and Wellbeing. The implementation of a hospital-wide safe patient handling and mobilisation programme was initiated and supported by hospital leadership within a major academic hospital in the greater Boston metropolitan area. The data used for the programme evaluation were collected as part of another project conducted by the Center for Work, Health, and Wellbeing at two major academic hospitals, which included the study hospital with the safe patient handling and mobilisation programme (Hospital A). As a reference for secular trends, the other hospital (B) shared similar characteristics, such as the number of beds $>500$, types of inpatient units, diagnosis-related groups, case mix and payer mix providing a concurrent comparison.

Prior to the initiation of this study, both hospitals had limited success in improving safe patient handling and mobilisation practices. ${ }^{15} 18$ While the hospitals had invested in lifting devices and slings, only a few isolated areas within the hospitals were using the equipment consistently. Prior efforts did not involve hospital leadership and staff beyond a few advocates and the occupational health staff.

All surveys and their consent forms and protocols were reviewed and approved by the Harvard Chan School's Office of Human Research Administration.

\section{The safe patient handling and mobilisation programme}

The goals for the hospital-wide programme were to provide staff strategies for safe mobilisation of patients to prevent associated worker injuries within an initiative to mobilise patients early and frequently. Programme leadership and coordination included a multidisciplinary oversight committee chaired by the Associate Chief Nurse of Quality and a collaborative coordination committee, including the Associate Chief, the occupational health ergonomist and the nursing business officer. Leadership support included participation of all inpatient nurse directors.
The committee developed a multicomponent programme that included key components identified by previous systematic reviews, including an organisational policy aimed at reducing injuries, the investment in equipment, broad-based training within the context of providing tools and risk assessments. ${ }^{13} 2021$ In addition, the programme included building a hospital-wide infrastructure for maintaining and servicing equipment, providing clean slings, embedding the use of equipment and practices into the care plan for each patient, implementing a mentoring programme to sustain training efforts and dissemination of new information and utilising a strong communication programme with leaders, workers and clients all within the framework of increasing patient mobility.

The coordination committee conducted a top to bottom review of systems and equipment (needs assessment). This included a review of patient populations and mobilisation needs, existing lift and transfer equipment in place, stakeholders, existing documentation, patient hand-off procedures, training programmes and materials, and internal communication resources. Programme rollout began in September 2012 and ended with worker training that occurred between December 2012 and April 2013.

The hospital expanded its investment in ceiling lifts, slings, sit-to stand devices (eg, mechanical floor-based stand-assist lifts), thoracic walkers, stand aids (eg, Stain Aid), air-assisted lateral transfer devices (eg, HoverJack and HoverMatt) and several portable floor lift devices (eg, Total Lift and EZ lift). Specialised inpatient care areas and rooms, including postanaesthesia care units, emergency department computerized tomography (CT) suites and radiology units, were all equipped with ceiling lifts with the exception of antenatal and postpartum units. In the antenatal and postpartum units, portable/floor/total lifts and associated slings were available on each unit. Ceiling lifts had weight limits of $625 \mathrm{lbs}(283 \mathrm{~kg})$, which could be increased with the addition of a second motor and bariatric capacity sling. Bed repositioning slings had maximum limit of $1000 \mathrm{lbs}(454 \mathrm{~kg})$. The hospital did not invest in friction-reducing plastic liners, which would have countered the no boost policy in place.

The coordinating committee developed processes ensuring that all equipment was in working order and portable devices were stored on the units and readily available for use. Linen services were responsible for ensuring that an adequate supply of sling types and sizes were consistently available. A preventive maintenance plan for all equipment was established. On each unit, a 'who to call for what' handbook was developed to provide staff with equipment descriptions, weight capacities, repair and training information to ensure any patient care worker could initiate corrective action when necessary.

The programme emphasised a patient mobility needs assessment, which identified specific protocols and tools as part a patient's treatment. A plan of care document and fields in the electronic medical forms reflected a patient's functional mobility status and equipment needed. ${ }^{22}$ These plans and forms integrated the identified needs into care practices ensuring continuity of care among any patient care staff, especially during patient hand offs. The patient mobility needs assessment was based on the Egress Test. ${ }^{22} 23$

Programme training was provided to all nurses, nurse directors and patient care assistants. An external consultant provided an online introductory module, followed by group training and one-on-one coaching and mentoring at the bedside. Training emphasised completing the mobility assessment to identify equipment needed, documenting the patient's mobility status and communicating patient mobility status during hand-off, and when a patient interacted with additional direct care providers. 
Additional training resources included laminated instructional cards at the bedside, instructions placed on all portable equipment and a 'decision guide'. New employees were (and continue to be) oriented by 'unit champions' in a simulation laboratory. The hospital back-filled employees so staff could attend training during work hours. Identified unit champions received additional training to support their roles as 'go to resources'.

The hospital implemented an internal marketing campaign to ensure programme visibility, including emails, an internal newsletter, recognition awards, rolling messages posted to TV monitors and presentations on programme progress to key committees within the hospital. The team also developed patient education materials for patients, family members and visitors that communicated programme goals and benefits.

\section{Programme evaluation}

The programme evaluation compared pre-postimplementation data from worker survey's collected at both hospitals before worker training (September 2012-January 2013) and afterwards (March-June 2014).

\section{Sample}

Eligible workers were employed during 2012, who worked in patient care units under the direction of a nurse manager, worked $>20$ hours per week ( $>0.5$ full-time equivalent) in Patient Care Services, and had direct patient care responsibilities. These included registered nurses, licensed practical nurses, clinical nurse specialists and patient care assistants. Workers assigned to environmental services and physical medicine staff (eg, physical therapy, occupational therapy) as well as postanaesthesia care, and the nursing float pool were not included.

\section{Worker survey data collection}

For Hospital A, we invited a random sample of $33 \%$ of eligible workers (866) to complete our online survey. For Hospital B, we also invited a random sample of 33\% (785) of all eligible workers except for workers in 8 units where we invited all (482). The 8 units were part of a proof-of-concept trial described previously. ${ }^{18}$ The survey informed participants that by completing the survey, they indicated consent.

\section{Measures}

Both surveys assessed work-place practices and worker selfreported pain. The assessment of safe patient handling practices contained three subscales: safe handling practices (2 questions), unsafe handling practices ( 3 questions) and patient repositioning (4 questions). ${ }^{15}$ The two safe patient practice questions asked how often workers used a (1) lifting device when a patient needed to be moved, and (2) sling or device to boost a patient in bed. The three unsafe patient handling practice questions asked how often workers (1) transferred patients who could not bear weight without the use of equipment but with the help of a coworker; (2) transferred patients who could not bear weight without the use of equipment or the help of a coworker; and (3) transferred patients who were combative patients. For these items, responses ranged from 'never (scored a 1)' to 'always (scored a 5)' and the scores for the two subscales were the average of the responses. The four patient repositioning questions asked how often workers: (1) made the bed with a patient in it; (2) repositioned a patient in a geriatric chair, wheelchair or regular chair; (3) transferred a patient from chair to bed or bed to chair; and (4) transferred a patient from chair to toilet or from toilet to chair. The responses were never, 1-5 times, 6-10 times in a shift or $10+$ times in a shift. The responses were converted to a number, $0,3,8$ and 13 , respectively. We summed these numbers for the three items to get the number of times worker had to reposition or transfer patient in a typical shift.

Both surveys assessed unit level safe patient handling practices and worker self-efficacy related to using safe patient handling equipment. ${ }^{15}$ The unit practices asked workers to indicate their agreement with statements about if they use patient lifting devices on their home unit whenever we need to move a patient, if nursing staff think that patient lifting devices are timeconsuming to use, and if Nursing staff will respond quickly if someone asks for help. The responses ranged from strongly disagree (scored a 1) to strongly agree (scored a 5). The three selfefficacy questions asked workers how confident were they that they have the skills to use patient lifting devices without asking for help, they can make the time to use patient lifting devices and they can find patient lifting devices when needed. The responses ranged from 'not confident at all' (scored a 1) to 'completely confident' (scored a 5). Additionally, we assessed ergonomic practices and safety practices measures.

Both surveys assessed self-reported pain in the past 3 months and pain severity in the past week. ${ }^{7}{ }^{18}$ For the past 3 months, any pain and pain in specific body regions was assessed using a modified question from the Pro-Care Survey (NordicQ). ${ }^{24}$ We also asked, "In general how much did this pain interfere with your normal work?" and assigned a positive value with responses of moderately, quite a bit or extremely. The surveys assessed musculoskeletal pain severity using an adapted Disabilities of the Arm, Shoulder, and Hand (DASH) questionnaire ${ }^{25}$ based on pain location (ie, in the low back; arm, shoulder or hand pain; tingling in their arm, shoulder or hand; pain in their legs or knees; and pain in their feet); responses were on a five-point scale from ' $0=$ none' to ' $4=$ extreme' and summed to provide a measure of pain severity during the past week.

To track training, the follow-up survey also asked about the type of safe patient handling and mobilisation training each worker received in the past 12 months. The responses included online courses, hands-on training, equipment manufacturing training and one-on-one training by a coworker or by the contractor/consultant.

\section{Administrative database}

The programme evaluation also compared recordable injury rates for two periods: the 12 months preceding the programme initiation (September 2011-August 2012) and the 12 months after (April 2013-March 2014) the worker training was completed. We used an integrated administrative database ${ }^{5}$ formed from three systems: a human resources database; the staffing database, which included worked shifts for all workers; and the occupational health services database. Human resources and staffing databases restricted the study cohort to nurses and patient care assistants in the eligible patient care services units. The occupational health services database contains all reported incidents and injuries for all employees. Injury descriptors included employee identifier, date of injury, body parts affected, nature of injury and cause of injury. These administrative data were not matched to the survey data. We calculated working hours by summing actual hours worked at a unit based on data from the staffing database. We converted these to full-time equivalents (FTE $=2000$ hours).

In addition, linen services in Hospital A tracked weekly sling usage and reported these data to the coordination committee.

\section{Statistical analysis}

Summary statistics were calculated for all survey outcomes and respondent demographics separately for the two hospitals. To 
account for the differential sampling fractions for Hospital B, summary statistics were computed using sampling weights within the SURVEYMEANS and SURVEYFREQ procedures of SAS.

To test the first hypothesis that work practices improved, we used analysis of covariance (ANCOVA) models with the survey scale as the dependent variable and time of survey (baseline/ follow-up) as the independent variable. An employee study ID number was included in the models as a random effect to control for subject-specific variation of participants who answered both surveys. To test the second hypothesis regarding pain, we used a generalised linear mixed model, with the pain outcomes as the dependent variable and time of survey as the independent variable and controlling for random employee effect.

To test the third hypothesis concerning injury rates, we first estimated recordable injury counts and Poisson injury rates per 100 FTEs in the pre and postperiods. Additionally, in order to compare rates over time, post-to-pre programme rate ratios, 95\% CIs and type III $p$ values were calculated using the Poisson regression with the individual worker as the unit of analysis. We also examined rates and ratios for subsets of injuries with various characteristics such as injuries with and without days away, specific body parts of interest (back and the neck or shoulder), causes of injury (lift/exertion) and nature of injury (pain or inflammation, contusion or bruise, and sprain or strains).

These analyses were completed separately for each of the two hospitals. All analyses were carried out using SAS Statistical software, V.9.3 (SAS Institute, Cary, North Carolina, USA).

\section{RESULTS}

Of the 866 workers invited to complete the surveys at Hospital A, 580 completed the preprogramme survey in 2012 and 499 completed the postprogramme survey in 2014 with 424 completing both. Of the 1267 workers invited to complete the surveys at Hospital B, 1011 completed the baseline survey in 2012 and 971 completed the follow-up in 2014 with 785 completing both. The sampled workers at baseline were primarily staff nurses, worked more than 30 hours per week, white, female and attended college (table 1). At follow-up, workers at the Hospital A reported higher participation in hands-on and one-on-one safe patient handling training as well as more policies that required the use of lifting devices than at Hospital B (table 2). Linen services at the Hospital A reported an increase in the number of laundered slings from 323 per week in 2012 to 498 per week in 2014.

Scores for safe patient handling and mobilisation practices improved significantly at follow-up for Hospital A (table 3). The safe patient handling scale increased while the unsafe patient handling scale and the patient repositioning scale both decreased. Scores for ergonomic practices also increased. Safety practices, unit level safe patient handling practices and worker efficacy scales remained unchanged. For Hospital B, all work practices scores remained unchanged during the same period except for safety practices and worker efficacy, both of which became worse (table 4).

There were no statistically significant differences in the percentage of respondents who reported pain during the past 3 months and moderate pain severity in the past week between baseline and follow-up for both hospitals.

The number of recordable injuries across all patient care units in Hospital A declined for the 12-month period postprogramme compared with the 12-month period prior (table 5). This decrease was evident for recordable injuries associated with
Table 1 Demographics of the survey respondents for both hospitals

\begin{tabular}{|c|c|c|}
\hline \multirow[b]{2}{*}{ Bivariates } & \multicolumn{2}{|l|}{ Baseline comparison } \\
\hline & $\begin{array}{l}\text { Study hospital }(A) \\
(N=580) \\
\%(N) \text { or } \\
\text { mean (SE) }\end{array}$ & $\begin{array}{l}\text { Comparison } \\
\text { hospital }(B)^{*} \\
\text { Weighted }(N=1011) \\
\%(N) \text { or mean }(S E)\end{array}$ \\
\hline \multicolumn{3}{|l|}{ Gender } \\
\hline Male & $6.5 \%(37)$ & $8.6 \%(189)$ \\
\hline Female & $93.5 \%(528)$ & $91.4 \%(2016)$ \\
\hline Age & $42.7( \pm 0.49)$ & $40.6( \pm 0.43)$ \\
\hline \multicolumn{3}{|l|}{ Occupation } \\
\hline Staff nurse & $81.3 \%(470)$ & $85.2 \%(1890)$ \\
\hline Patient care associate & $16.6 \%(96)$ & $10.5 \%(233)$ \\
\hline Clinical nurse specialist & $2.1 \%(12)$ & $2.7 \%(61)$ \\
\hline Other & $0.0 \%(0)$ & $1.5 \%(33)$ \\
\hline \multicolumn{3}{|l|}{ Hours worked (hours) } \\
\hline$<30$ & $21.6 \%(125)$ & $20.5 \%(456)$ \\
\hline $30-34$ & $12.6 \%(73)$ & $9.0 \%(200)$ \\
\hline $35-39$ & $42.3 \%(245)$ & $38.0 \%(842)$ \\
\hline $40-44$ & $21.9 \%(127)$ & $29.0 \%(643)$ \\
\hline Over 44 & $1.6 \%(9)$ & $3.5 \%(77)$ \\
\hline \multicolumn{3}{|l|}{ Typical shift } \\
\hline Day & $35.5 \%(205)$ & $22.0 \%(487)$ \\
\hline Evening & $7.1 \%(41)$ & $5.8 \%(128)$ \\
\hline Night & $31.5 \%(182)$ & $21.0 \%(466)$ \\
\hline Other & $26.0 \%(150)$ & $51.2 \%(1135)$ \\
\hline \multicolumn{3}{|l|}{ Race/ethnicity } \\
\hline Hispanic & $5.8 \%(33)$ & $3.2 \%(71)$ \\
\hline White & $75.7 \%(431)$ & $82.1 \%(1814)$ \\
\hline Black & $12.8 \%(73)$ & $6.6 \%(146)$ \\
\hline Mixed race/other & $5.6 \%(32)$ & $8.1 \%(178)$ \\
\hline \multicolumn{3}{|l|}{ Education } \\
\hline Grade $12 /$ GED or less & $4.6 \%(26)$ & $1.4 \%(31)$ \\
\hline $\begin{array}{l}1-3 \text { years of college or tech } \\
\text { school }\end{array}$ & $21.9 \%(124)$ & $15.8 \%(345)$ \\
\hline 4-year college degree (graduated) & $55.2 \%(312)$ & $65.1 \%(1423)$ \\
\hline Any graduate school & $18.2 \%(103)$ & $17.7 \%(388)$ \\
\hline \multicolumn{3}{|l|}{ Pain outcomes } \\
\hline \multicolumn{3}{|l|}{ Any pain } \\
\hline No & $20.3 \%(116)$ & $21.1 \%(462)$ \\
\hline Yes & $79.7 \%(456)$ & $78.9 \%(1722)$ \\
\hline \multicolumn{3}{|l|}{ Work interference } \\
\hline No & $69.8 \%(399)$ & $73.7 \%(1603)$ \\
\hline Yes & $30.2 \%(173)$ & $26.3 \%(572)$ \\
\hline Pain severity scale & $2.8( \pm 0.12)$ & $2.5( \pm 0.08)$ \\
\hline \multicolumn{3}{|l|}{ Pain severity scale $>3$} \\
\hline No & $54.8 \%(308)$ & $59.4 \%(1308)$ \\
\hline Yes & $45.2 \%(254)$ & $40.6 \%(895)$ \\
\hline \multicolumn{3}{|l|}{ Patient handling practices } \\
\hline SPH (1-5) & $2.3( \pm 0.04)$ & $2.4( \pm 0.04)$ \\
\hline Unsafe patient handling scale (1-5) & $2.1( \pm 0.03)$ & $2.2( \pm 0.02)$ \\
\hline Patient repositioning (lifts/shift) & $12.2( \pm 0.38)$ & $12.7( \pm 0.34)$ \\
\hline \multicolumn{3}{|l|}{ SPH norms and efficacy } \\
\hline Work-unit SPH norms $(1-5+)$ & $3.4( \pm 0.03)$ & $3.4( \pm 0.02)$ \\
\hline Self-efficacy SPH device use (1-5+) & $3.5( \pm 0.05)$ & $3.6( \pm 0.04)$ \\
\hline \multicolumn{3}{|l|}{ Other work practices } \\
\hline Safety practices (5Q) scale & $3.6( \pm 0.03)$ & $3.9( \pm 0.03)$ \\
\hline Ergonomics practices (6Q) scale & $3.0( \pm 0.04)$ & $3.1( \pm 0.03)$ \\
\hline \multicolumn{3}{|l|}{ Unit category } \\
\hline ER & $5.0 \%(29)$ & $8.2 \%(182)$ \\
\hline OR & $8.3 \%(48)$ & $11.6 \%(257)$ \\
\hline
\end{tabular}


Table 1 Continued

\begin{tabular}{|c|c|c|}
\hline \multirow[b]{2}{*}{ Bivariates } & \multicolumn{2}{|l|}{ Baseline comparison } \\
\hline & $\begin{array}{l}\text { Study hospital (A) } \\
(\mathrm{N}=580) \\
\%(\mathrm{~N}) \text { or } \\
\text { mean (SE) }\end{array}$ & $\begin{array}{l}\text { Comparison } \\
\text { hospital }(B)^{*} \\
\text { Weighted }(N=1011) \\
\%(N) \text { or mean }(S E)\end{array}$ \\
\hline Adult medicine/surgery & $35.9 \%(208)$ & $40.9 \%(909)$ \\
\hline Adult ICU & $16.7 \%(97)$ & $14.5 \%(323)$ \\
\hline Stepdown & $9.5 \%(55)$ & $1.9 \%(42)$ \\
\hline Paediatric medicine/surgery & $0.0 \%(0)$ & $3.2 \%(72)$ \\
\hline Paediatric ICU/NICU & $5.9 \%(34)$ & $4.0 \%(89)$ \\
\hline Psychiatry & $0.0 \%(0)$ & $2.8 \%(63)$ \\
\hline OB-postpartum & $10.9 \%(63)$ & $7.8 \%(174)$ \\
\hline Float pool & $6.7 \%(39)$ & $2.6 \%(57)$ \\
\hline Orthopaedics & $1.2 \%(7)$ & $2.4 \%(54)$ \\
\hline
\end{tabular}

*Sampling weights were applied to comparison Hospital B workers based on oversampling of eight study units discussed in Sorensen et al. ${ }^{18}$

$E R$, emergency room; GED, general education development; ICU, intensive care unit; NICU, neonatal intensive care unit; OR, operating room; SPH, safe patient handling.

lifting and exertion, which saw a $27 \%$ reduction. All injuries (13\%), neck/shoulder (32\%) and pain/inflammation (22\%) injuries decreased with marginal significance. Changes at Hospital B were not significant.

\section{DISCUSSION}

The goal of this study was to evaluate the effects of a hospitalwide multiple-component safe patient handling and mobilisation programme that was part of a larger programme to increase patient mobility. Based on organisational framework for worker health and safety, ${ }^{26}$ we examined patient handing practices, self- reported pain and recordable injury outcomes prior to and after the implementation of the programme. We saw improvements in all of these measures after the implementation of the programme, supporting our stated hypotheses.

These findings point to a significant value added to safe patient handling programmes directed at promoting earlier mobilisation of patients in terms of reductions in worker injuries. A unique contribution of the study is that this intervention occurred in the special and new context where the primary focus was on improving patient care through earlier and more frequent mobilisation of patients. Healthcare is moving in this new direction, which without appropriate safe guards will likely increase the risks to employee safety and health. With the increasing focus on improving patient care through earlier mobilisation of patients, these findings highlight an important benefit derived from integrating employee safety interventions into patient mobilisation efforts. This integration process necessitated a broader engagement of leadership, coordination across multiple departments and a system-wide communication effort. In the end, the programme succeeded in integrating worker safety practices within the occupational culture of providing quality care for patients. ${ }^{17}$

These positive results provide support for strategic and operational coordination of policies, programmes and practices designed to embed best practices for safe patient handling and mobilisation into a systems-wide initiative. In the comparison Hospital B, the Center for Work, Health, and Wellbeing implemented a unit level intervention in 4 units. ${ }^{18}$ The intervention targeted safety patient handling practices as well as worker health, including sleep, diet and physical activity. In contrast, the unit level intervention saw no significant effects on the study outcome, including low back pain (or any other outcome measures). The process tracking documented few changes in policy and practices at the unit level with many of the

Table 2 Safe patient handling/mobility training and policies

\begin{tabular}{|c|c|c|}
\hline \multirow[b]{2}{*}{ Hospital bivariates } & \multicolumn{2}{|c|}{ Follow-up comparison } \\
\hline & $\begin{array}{l}\text { Study hospital A } \\
\text { (N=499) } \\
\%(\mathrm{~N})\end{array}$ & $\begin{array}{l}\text { Comparison hospital } \\
B^{*}(N=971) \\
\%(N)\end{array}$ \\
\hline \multicolumn{3}{|l|}{ Training } \\
\hline \multicolumn{3}{|c|}{ In the past 12 months, please tell us ways you have received safe patient handling/mobility training } \\
\hline Online coursework and/or seminars & $41.2(185)$ & $53.4(1016)$ \\
\hline Hands-on classroom group training at the hospital & $54.1(253)$ & $16.0(298)$ \\
\hline Instruction in equipment operations by the lifting equipment manufacturer & $46.2(212)$ & $20.2(378)$ \\
\hline One-on-one training by a coworker, unit champion or supervisor & $39.6(179)$ & $31.4(596)$ \\
\hline One-on-one training by a 'PREVENT/Get-A-lift' staff & $20.4(91)$ & $6.8(126)$ \\
\hline \multicolumn{3}{|l|}{ Policies } \\
\hline \multicolumn{3}{|l|}{ Assessment of patient mobility status } \\
\hline Required for all patients (ie, part of standard patient care) & $66.9(330)$ & $67.3(1339)$ \\
\hline Required only for patients whose mobility is impaired & $7.9(39)$ & $9.4(186)$ \\
\hline Not required but is strongly encouraged & $7.9(39)$ & $8.0(160)$ \\
\hline Not required or strongly encouraged & $3.2(16)$ & $1.4(27)$ \\
\hline Does not apply to my home unit & $14.0(69)$ & $14.0(278)$ \\
\hline \multicolumn{3}{|l|}{ Use of patient lifting devices } \\
\hline Required for all patients (ie, is part of standard patient care) & $11.1(55)$ & $9.4(187)$ \\
\hline Required only for patients whose mobility is impaired & $37.4(185)$ & $28.8(575)$ \\
\hline Not required but is strongly encouraged & $23.9(118)$ & $31.8(633)$ \\
\hline Not required or strongly encouraged & $7.9(39)$ & $11.9(236)$ \\
\hline Does not apply to my home unit & $19.6(97)$ & $18.2(363)$ \\
\hline
\end{tabular}


Table 3 Work practices from the pre-postprogramme surveys

\begin{tabular}{lccc}
\hline & Baseline adjusted mean $( \pm$ SE) & Follow-up adjusted mean $( \pm$ SE) & Adjusted mean difference $(95 \%$ Cl) \\
\hline Study hospital (A) & & & \\
$\quad$ Safe Patient Handling (1-5) & $2.24( \pm 0.04)$ & $2.59( \pm 0.05)$ & $0.35(0.27$ to 0.43$)$ \\
Unsafe patient handling (1-5) & $2.15( \pm 0.03)$ & $2.04( \pm 0.03)$ & $-0.11(-0.18$ to -0.04$)$ \\
Patient repositioning (lifts/shift) & $12.13( \pm 0.36)$ & $11.04( \pm 0.38)$ & $-1.08(-1.81$ to -0.35$)$ \\
Work-unit SPH norms & $3.38( \pm 0.03)$ & $3.39( \pm 0.03)$ & $0.01(-0.05$ to 0.06$)$ \\
Self-efficacy to use SPH devices & $3.51( \pm 0.05)$ & $3.43( \pm 0.05)$ & $-0.09(-0.19$ to 0.01$)$ \\
Safety practices & $3.55( \pm 0.03)$ & $3.59( \pm 0.03)$ & $0.04(-0.02$ to 0.11$)$ \\
Ergonomics practices & $3.04( \pm 0.04)$ & $3.11( \pm 0.04)$ & $0.08(0.00$ to 0.15$)$ \\
Comparison hospital (B) & & & \\
Safe Patient Handling & $2.43( \pm 0.03)$ & $2.44( \pm 0.03)$ & $0.00(-0.05$ to 0.06$)$ \\
Unsafe patient handling & $2.17( \pm 0.02)$ & $2.19( \pm 0.02)$ & $0.01(-0.03$ to 0.06$)$ \\
Patient repositioning (lifts/shift) & $12.66( \pm 0.29)$ & $12.57( \pm 0.29)$ & $-0.09(-0.58$ to 0.40$)$ \\
Work-unit SPH norms & $3.37( \pm 0.02)$ & $3.37( \pm 0.02)$ & $-0.00(-0.04$ to 0.04$)$ \\
Self-efficacy to use SPH devices & $3.66( \pm 0.04)$ & $3.58( \pm 0.04)$ & $-0.08(-0.15$ to -0.02$)$ \\
Safety practices & $3.90( \pm 0.02)$ & $3.82( \pm 0.02)$ & $-0.08(-0.13$ to -0.03$)$ \\
Ergonomics practices & $3.17( \pm 0.03)$ & $3.14( \pm 0.03)$ & $-0.03(-0.08$ to 0.02$)$ \\
\hline
\end{tabular}

Mixed-model ANCOVA analysis was performed controlling for employee ID.

*Italicised values indicate significant $(p<0.05)$ differences between preprogramme and postprogramme.

ANCOVA, analysis of covariance; SPH, safe patient handling.

intervention activities competing with patient care priorities. The qualitative data identified a need for system-wide norms, polices and infrastructure supports that can be translated to the units. In addition, a key barriers to worker involvement in the intervention was competing patient care priorities. ${ }^{17}$

A key and unique element of the programme was embedding the use of safe patient handling methods and tools into the plan of care for each patient aligning the programme's goals with the occupational culture of patient care. ${ }^{17}$ This integration was emphasised throughout the programme, including, for example, worker training and working with the information technology group. The worker training consisted of a combination of formats and tools with a focus on bedside mentoring to ensure that the mobility needs associated with a particular patient were addressed. The training emphasised the use of patient functional mobility assessment to identify mechanical devices in the patient mobilisation care plan and to communicate this assessment and the devices needed to others involved in a patient's care. ${ }^{2}$ This allowed a customised approach for the patients' needs that vary within and across hospital units. The team also worked with information technology to include mobilisation assessment, and patient treatment plans that required specific equipment in the electronic medical records. Therefore, once a patient's needs were assessed and documented, other caregivers were given information on what to do to safely mobilise and treat a patient through these electronic medical records.

A necessary component of this programme's success was the hospital leadership's commitment. The upper and middle-level managers created the appropriate climate, supported workforce development and provided resources needed for all aspects of this comprehensive programme. ${ }^{27} 28$ One example was providing workers with the time and support to be off their unit during work time to participate in training. ${ }^{29}$ In addition, the management commitment provided the resources to invest in mechanical lifts and slings throughout the hospital, a necessary component of such programmes. ${ }^{30}$ These mechanical lifts are essential in reducing the physical load on the spine. ${ }^{13} 1431$

This programme supports the idea that activities and responsibilities for protecting workers health and safety as well as patient must be shared and integrated over all aspects of the organisation. $^{32}$ The programme focused on creating a crossorganisational infrastructure to share these activities. For example, the programme staff recruited support from the linen services to integrate management of slings into their procedures.

Table 4 Self-reported pain in the past 3 months and pain severity in the last week

\begin{tabular}{llll}
\hline & Baseline adjusted \% ( \pm SE) & Follow-up adjusted \% ( \pm SE) & Adjusted OR (95\% Cl) \\
\hline $\begin{array}{l}\text { Study hospital }(A) \\
\quad \text { Any pain }\end{array}$ & $80.42 \%( \pm 1.79)$ & $76.43 \%( \pm 2.08)$ & $0.79(0.58$ to 1.07$)$ \\
Low back pain & $55.21 \%( \pm 2.33)$ & $49.99 \%( \pm 2.52)$ & $0.81(0.63$ to 1.04$)$ \\
$\quad$ Shoulder/neck pain & $43.04 \%( \pm 2.29)$ & $40.56 \%( \pm 2.45)$ & $0.90(0.70$ to 1.16$)$ \\
$\quad$ Work interference & $29.64 \%( \pm 2.07)$ & $27.92 \%( \pm 2.21)$ & $0.92(0.70$ to 1.21$)$ \\
$\quad$ Moderate pain severity $>3$ & $44.84 \%( \pm 2.40)$ & $43.74 \%( \pm 2.55)$ & $0.96(0.74$ to 1.24$)$ \\
Comparison hospital $(B)$ & & & \\
$\quad$ Any pain & $78.86 \%( \pm 1.42)$ & $77.24 \%( \pm 1.49)$ & $0.91(0.74$ to 1.11$)$ \\
$\quad$ Low back pain & $53.66 \%( \pm 1.70)$ & $53.35 \%( \pm 1.78)$ & $0.99(0.84$ to 1.16$)$ \\
Shoulder/neck pain & $42.43 \%( \pm 1.70)$ & $40.26 \%( \pm 1.75)$ & $0.91(0.77$ to 1.08$)$ \\
$\quad$ Work interference & $26.32 \%( \pm 1.54)$ & $25.56 \%( \pm 1.60)$ & $0.96(0.79$ to 1.16$)$ \\
$\quad$ Moderate pain severity $>3$ & $40.61 \%( \pm 1.70)$ & $42.11 \%( \pm 1.76)$ & $1.06(0.91$ to 1.25$)$ \\
\hline Mixed-model analysis of covariance (ANCOVA) analysis was performed controlling for employee ID. & &
\end{tabular}


Table 5 Recordable injury rates for the patient care units

\begin{tabular}{|c|c|c|c|c|c|c|c|c|}
\hline \multirow{2}{*}{$\begin{array}{l}\text { Study hospital (A) } \\
\text { Injury category }\end{array}$} & \multicolumn{3}{|c|}{12 months preprogramme $(n=2149)$} & \multicolumn{3}{|c|}{12 months postprogramme $(n=2131)$} & \multirow[b]{2}{*}{ Rate ratio* } & \multirow[b]{2}{*}{$95 \% \mathrm{Cl}$} \\
\hline & Injury count & Rate/100 FTEs & $95 \% \mathrm{Cl}$ & Injury count & Rate/100 FTEs & $95 \% \mathrm{Cl}$ & & \\
\hline All injuries & 448 & 20.8 & 19.0 to 22.9 & 388 & 18.2 & 16.5 to 20.1 & 0.873 & 0.76 to 1.00 \\
\hline \multicolumn{9}{|l|}{ Lost days } \\
\hline Days away injuries & 306 & 14.2 & 12.7 to 15.9 & 261 & 12.3 & 10.9 to 13.8 & 0.860 & 0.73 to 1.01 \\
\hline No days away injuries & 142 & 6.6 & 5.6 to 7.8 & 127 & 6.0 & 5.0 to 7.1 & 0.902 & 0.71 to 1.15 \\
\hline \multicolumn{9}{|l|}{ Body part } \\
\hline Back & 121 & 5.6 & 4.7 to 6.7 & 95 & 4.5 & 3.7 to 5.5 & 0.792 & 0.61 to 1.04 \\
\hline Neck/shoulder & 64 & 3.0 & 2.3 to 3.8 & 43 & 2.0 & 1.5 to 2.7 & 0.678 & 0.46 to 1.00 \\
\hline \multicolumn{9}{|l|}{ Cause of injury } \\
\hline Lift/exertion injuries & 239 & 11.1 & 9.8 to 12.6 & 174 & 8.2 & 7.0 to 9.5 & 0.734 & 0.60 to 0.89 \\
\hline \multicolumn{9}{|l|}{ Nature of injury } \\
\hline Pain/inflammation injuries & 153 & 7.1 & 6.1 to 8.3 & 119 & 5.6 & 4.7 to 6.7 & 0.784 & 0.62 to 1.00 \\
\hline Contusion/bruise injuries & 71 & 3.3 & 2.6 to 4.1 & 62 & 2.9 & 2.3 to 3.7 & 0.881 & 0.63 to 1.24 \\
\hline Sprain/strain injuries & 106 & 4.9 & 4.1 to 6.0 & 86 & 4.0 & 3.3 to 5.0 & 0.818 & 0.62 to 1.09 \\
\hline \multirow{2}{*}{$\begin{array}{l}\text { Comparison hospital (B) } \\
\text { Injury category }\end{array}$} & \multicolumn{3}{|c|}{12 months preprogramme $(\mathrm{N}=2348)$} & \multicolumn{3}{|c|}{12 months post-programme $(n=2414)$} & & \\
\hline & Injury count & Rate per 100 FTEs & $95 \% \mathrm{Cl}$ & Injury count & Rate per 100 FTEs & $95 \% \mathrm{Cl}$ & Rate ratio & $95 \% \mathrm{Cl}$ \\
\hline All injuries & 197 & 8.39 & 7.30 to 9.65 & 180 & 7.46 & 6.44 to 8.63 & 0.889 & 0.73 to 1.09 \\
\hline \multicolumn{9}{|l|}{ Lost days } \\
\hline Days away injuries & 70 & 2.98 & 2.36 to 3.77 & 57 & 2.36 & 1.82 to 3.06 & 0.792 & 0.56 to 1.12 \\
\hline No days away injuries & 127 & 5.41 & 4.55 to 6.44 & 123 & 5.10 & 4.27 to 6.08 & 0.942 & 0.74 to 1.21 \\
\hline \multicolumn{9}{|l|}{ Body part } \\
\hline Back & 33 & 1.41 & 1.00 to 1.98 & 30 & 1.24 & 0.87 to 1.78 & 0.884 & 0.54 to 1.45 \\
\hline Neck/shoulder & 15 & 0.64 & 0.39 to 1.06 & 11 & 0.46 & 0.25 to 0.82 & 0.713 & 0.33 to 1.55 \\
\hline \multicolumn{9}{|l|}{ Cause of injury } \\
\hline Lift/exertion injuries & 56 & 2.39 & 1.84 to 3.10 & 48 & 1.99 & 1.50 to 2.64 & 0.834 & 0.57 to 1.23 \\
\hline \multicolumn{9}{|l|}{ Nature of injury } \\
\hline Pain/inflammation injuries & 42 & 1.79 & 1.32 to 2.42 & 29 & 1.20 & 0.83 to 1.73 & 0.672 & 0.42 to 1.08 \\
\hline Contusion/bruise injuries & 19 & 0.81 & 0.52 to 1.27 & 17 & 0.70 & 0.44 to 1.13 & 0.870 & 0.45 to 1.67 \\
\hline Sprain/strain injuries & 25 & 1.06 & 0.72 to 1.58 & 28 & 1.16 & 0.80 to 1.68 & 1.089 & 0.64 to 1.87 \\
\hline
\end{tabular}

Through proactive sling inventory management, this service unit ensured slings were always available to workers on the patient units.

The worker survey and integrated injury and payroll administrative database established by the Center for Work, Health and Wellbeing in collaboration with Partners HealthCare provided a unique opportunity to evaluate this programme in more depth than would have been possible otherwise. The concurrent comparison to the reference hospital suggests that changes observed in the survey data and perhaps the administrative data in Hospital A were a result of the programme and not due to a testing effect or historical trend. While baseline injury rates were quite a bit different between the two hospitals, self-reported pain levels were similar, which may indicate different pathways for reporting in the two hospitals. ${ }^{33}$ Furthermore, the differences in the change in the injury rates between the two hospitals followed similar differences in the changes observed in self-reported pain. Moreover, despite the differences between the two hospitals, the populations studied were from the same types of units and the self-reported measures of work practices and pain outcomes were very similar at baseline (table 1).

These findings have to be considered within the context of the study. The programme did not address all types of musculoskeletal disorders and we did not observe a reduction in other types of injuries. There are many other injury hazards within patient care units that can contribute to work-related injuries that may need other types of interventions; ${ }^{15}{ }^{34}$ however, we did not see an increase in injuries and pain in these other areas, suggesting the programme did not shift the injuries to other regions of the body. Our patient handing practice outcomes were self-reported; however, there was a large increase in the use of slings, indicating that through the programme evaluation, there was a corresponding change in the demand for and use of slings associated with the use of mechanical lifts. This supports the concept that the changes observed in the self-reported patient handling practices scales reflect true changes in work practices. These safe practices measures are similar to the compliance measures of Fray and Hignett. ${ }^{35}$

The levels of self-reported pain were high, yet, similar to levels we have observed in these hospitals in prior studies. 73637 Similarly, while the changes in pain outcomes were nonsignificant; the observed trends were similar to the trends in the administrative databases. ${ }^{7637}$ Furthermore, this study focused on nurses and patient care assistants assigned to specific inpatient care units. There are many other workers within the hospital that interact with patient mobility, including physical and occupational therapist.

In conclusion, we saw that the systems approach of a multicomponent safe patient handling and mobilisation programme administered across hospital organisations with strong leadership commitment and support can have positive effects on 
worker injury outcomes. This research suggests that hospitals should consider prescribing safe patient handling and mobility equipment and practices into the specific and individualised care plan for each patient as part of a comprehensive safety patient handling programme.

\section{Author affiliations}

Department of Physical Therapy, Movement, and Rehabilitation Sciences, Bouvé College of Health Sciences, Northeastern University, Boston, Massachusetts, USA ${ }^{2}$ Department of Environmental Health and The Center for Work, Health, and Wellbeing, Harvard T.H. Chan School of Public Health, Boston, Massachusetts, USA ${ }^{3}$ Department of Occupational Health Services, Partners HealthCare System, Boston, Massachusetts, USA

${ }^{4}$ Center for Nursing Excellence, Brigham and Women's Hospital, Boston, Massachusetts, USA

${ }^{5}$ Patient Care Services Center for Nursing Excellence, Brigham and Women's Hospital, Boston, Massachusetts, USA

${ }^{6}$ Center of Community Based Research, Dana-Farber Cancer Institute, Boston, Massachusetts, USA

${ }^{7}$ New England Research Institutes, Watertown, Massachusetts, USA

${ }^{8}$ Department of Orthopaedic Surgery, Brigham and Women's Hospital, Boston, Massachusetts, USA

${ }^{9}$ Department of Environmental Health, Boston University School of Public Health, Boston, Massachusetts, USA

${ }^{10}$ Department of Social and Behavioral Sciences Health and The Center for Work, Health, and Wellbeing, Harvard T.H. Chan School of Public Health, Boston, Massachusetts, USA

${ }^{11}$ Boston College Law School, Newton Centre, Massachusetts, USA

${ }^{12}$ Department of Medicine, Harvard Medical School, Boston, Massachusetts, USA

Acknowledgements This study would not have been accomplished without the participation of Partners HealthCare System and leadership from Dennis Colling and Kurt Westerman. The authors would like to thank Kevin Hulme and the Study Hospital inpatient nursing directors and educators as well as Partners Occupational Health Services, including Marlene Freeley for her guidance, Terry Orechia for programming support and Aaron Ross for field support. They thank Betty Bogue of PREVENT/Get A Lift and her team. They also thank Ruth Lederman for her leadership in survey data collection; and the Health Communication Core and Survey and Data Management Core at the Dana-Farber/Harvard Cancer Center.

Funding The programme evaluation was supported by a grant from the National Occupational for Safety and Health (U19 OH008861) for the Harvard T.H. Chan School of Public Health Center for Work, Health and Well-being. Additional support was provided by the National Institute of Arthritis and Musculoskeletal and Skin Diseases of the National Institutes of Health under award number T32AR055885. The programme itself was funded by Partners HealthCare.

Competing interests None declared.

Ethics approval Harvard T.H. Chan School of Public Health.

Provenance and peer review Not commissioned; externally peer reviewed.

\section{REFERENCES}

1 Clark DE, Lowman JD, Griffin RL, et al. Effectiveness of an early mobilization protocol in a trauma and burns intensive care unit: a retrospective cohort study. Phys Ther 2013;93:186-96.

2 Kohn LT, Corrigan JM, Donaldson MS. To err is human: building a safer health system. Washington, DC: National Academy of Sciences, 2000.

3 Nelson A, Collins J, Siddharthan K, et al. Link between safe patient handling and patient outcomes in long-term care. Rehabil Nurs 2008;33:33-43.

4 United States Bureau of Labor Statistics. Case and Demographic Characteristics for Work-related Injuries and IIInesses Involving Days away from Work. Secondary Case and Demographic Characteristics for Work-related Injuries and Illnesses Involving Days away from Work. 2013. http://bls.gov/iif/oshcdnew.htm

5 Boden LI, Sembajwe G, Tveito TH, et al. Occupational injuries among nurses and aides in a hospital setting. Am J Ind Med 2012;55:117-26.

6 Rodriguez-Acosta RL, Richardson DB, Lipscomb HJ, et al. Occupational injuries among aides and nurses in acute care. Am I Ind Med 2009;52:953-64.

7 Dennerlein JT, Hopcia K, Sembajwe G, et al. Ergonomic practices within patient care units are associated with musculoskeletal pain and limitations. Am J Ind Med 2012:55:107-16.

8 Holtermann A, Clausen T, Jorgensen MB, et al. Patient handling and risk for developing persistent low-back pain among female healthcare workers. Scand J Work Environ Health 2013:39:164-9.

9 Gucer PW, Gaitens J, Oliver M, et al. Sit-stand powered mechanical lifts in long-term care and resident quality indicators. J Occup Environ Med 2013;55:36-44.
10 The Joint Commission. Improving patient and worker safety: opportunities for synergy, collaboration and innovation. Oakbrook Terrace, IL: The Joint Commission, 2012. http://www.jointcommission.org/

11 Occupational Safety and Health Administration of the United States. Injury and Illness Prevention Program: White Paper. Secondary Injury and IIlness Prevention Program: White Paper 2012. https://www.osha.gov/dsg/topics/safetyhealth/ OSHAwhite-paper-january2012sm.pdf

12 National Institute for Occupational Safety and Health (US). Essential Elements of Effective Workplace Programs and Policies for Improving Worker Health and Wellbeing. Secondary Essential Elements of Effective Workplace Programs and Policies for Improving Worker Health and Wellbeing. 2008. http://www.cdc.gov/ niosh/worklife/essentials.html

13 Tullar JM, Brewer S, Amick BC III, et al. Occupational safety and health interventions to reduce musculoskeletal symptoms in the health care sector. J Occup Rehabil 2010;20:199-219.

14 Dawson AP, McLennan SN, Schiller SD, et al. Interventions to prevent back pain and back injury in nurses: a systematic review. Occup Environ Med 2007;64:642-50.

15 Caspi CE, Dennerlein JT, Kenwood C, et al. Results of a pilot intervention to improve health and safety for health care workers. J Occup Environ Med 2013;55:1449-55.

16 Davis L, Miner C, Laramie A, et al. Moving into the Future: Promoting safe patient handling for worker and patient safety in Massachusetts hospitals. Occupational Health Surveillance Program. Boston: Commonwealth of Massachusetts, 2014.

17 Myers DJ, Schoenfisch AL, Lipscomb HJ. Cultural influences on workplace safety: an example of hospital workers' adoption of patient lifting devices. Saf Sci 2012;50:494-501.

18 Sorensen G, Nagler EM, Hashimoto D, et al. Implementing an integrated health protection/health promotion intervention in the hospital setting: lessons learned from the Be Well, Work Well study. J Occup Environ Med 2016;58:185-94.

19 Tveito TH, Sembajwe G, Boden LI, et al. Impact of organizational policies and practices on workplace injuries in a hospital setting. J Occup Environ Med 2014:56:802-8.

20 Hignett $\mathrm{S}$, Crumpton E, Ruszala S, et al. Evidence-based patient handling: systematic review. Nurs Stand 2003;17:33-6.

21 Bos EH, Krol B, Van Der Star A, et al. The effects of occupational interventions on reduction of musculoskeletal symptoms in the nursing profession. Ergonomics 2006;49:706-23.

22 Dionne M. Introducing the Egress test: a simple screen tool to predict safety of bariatric patient transfers. Phys Ther Rehab Med 2004;15:39.

23 Boynton T, Kelly L, Perez A. Implementing a mobility assessment tool for nurses. American Nurse Today 2014;9:13-16.

24 Kuorinka I, Jonsson B, Kilbom A, et al. Standardized Nordic Questionnaires for the analysis of musculoskeletal symptoms. Appl Ergon 1987;18:233-7.

25 Hudak PL, Amadio PC, Bombardier C. Development of an upper extremity outcome measure: the DASH (disabilities of the arm, shoulder and hand) [corrected]. The Upper Extremity Collaborative Group (UECG). Am J Ind Med 1996;29:602-8.

26 Sorensen G, McLellan D, Dennerlein JT, et al. Integrating worksite health protection and health promotion: a conceptual model for intervention and research. Prev Med 2016;91:188-96.

27 Gershon RR, Karkashian CD, Grosch JW, et al. Hospital safety climate and its relationship with safe work practices and workplace exposure incidents. Am J Infect Control 2000;28:211-21.

28 Eriksen W, Bruusgaard D, Knardahl S. Work factors as predictors of intense or disabling low back pain; a prospective study of nurses' aides. Occup Environ Med 2004;61:398-404.

29 Evanoff BA, Bohr PC, Wolf LD. Effects of a participatory ergonomics team among hospital orderlies. Am J Ind Med 1999;35:358-65.

30 Evanoff $B$, Wolf $\mathrm{L}$, Aton $\mathrm{E}$, et al. Reduction in injury rates in nursing personnel through introduction of mechanical lifts in the workplace. Am J Ind Med 2003:44:451-7.

31 Marras WS, Davis KG, Kirking BC, et al. A comprehensive analysis of low-back disorder risk and spinal loading during the transferring and repositioning of patients using different techniques. Ergonomics 1999;42:904-26.

32 Sorensen G, McLellan D, Dennerlein JT, et al. Integration of health protection and health promotion: rationale, indicators, and metrics. J Occup Environ Med 2013;55 (12 Suppl):S12-18.

33 Boden LI, Petrofsky YV, Hopcia K, et al. Understanding the hospital sharps injury reporting pathway. Am J Ind Med 2015;58:282-9.

34 Van Eerd D, Munhall C, Irvin E, et al. Effectiveness of workplace interventions in the prevention of upper extremity musculoskeletal disorders and symptoms: an update of the evidence. Occup Environ Med 2016;73:62-70.

35 Fray M, Hignett S. TROPHI: development of a tool to measure complex, multi-factorial patient handling interventions. Ergonomics 2013;56:1280-94.

36 Reme SE, Shaw WS, Boden LI, et al. Worker assessments of organizational practices and psychosocial work environment are associated with musculoskeletal injuries in hospital patient care workers. Am J Ind Med 2014:57:810-18.

37 Sorensen G, Stoddard AM, Stoffel S, et al. The role of the work context in multiple wellness outcomes for hospital patient care workers. J Occup Environ Med 2011;53:899-910. 